\title{
Posterior fixation can further improve the segmental alignment of lumbar degenerative spondylolisthesis with oblique lumbar interbody fusion
}

\author{
Jingye Wu, Tenghui Ge, Ning Zhang, Jianing Li, Wei Tian and Yuqing Sun * (D)
}

\begin{abstract}
Background: For patients with degenerative spondylolisthesis, whether additional posterior fixation can further improve segmental alignment is unknown, compared with stand-alone cage insertion in oblique lumbar interbody fusion (OLIF) procedure. The aim of this study was to compare changes of the radiographical segmental alignment following stand-alone cage insertion and additional posterior fixation in the same procedure setting of OLIF for patients with degenerative spondylolisthesis.
\end{abstract}

Methods: A retrospective observational study. Selected consecutive patients with degenerative spondylolisthesis underwent OLIF procedure from July 2017 to August 2019. Five radiographic parameters of disc height (DH), DHAnterior, DH-Posterior, slip ratio and segmental lordosis (SL) were measured on preoperative CT scans and intraoperative fluoroscopic images. Comparisons of those radiographic parameters prior to cage insertion, following cage insertion and following posterior fixation were performed.

Results: A total of thirty-three patients including six males and twenty-seven females, with an average age of $66.9 \pm 8.7$ years, were reviewed. Totally thirty-six slipped levels were assessed with thirty levels at $L 4 / 5$, four at $L 3 / 4$ and two at L2/3. Intraoperatively, with only anterior cage support, DH was increased from $8.2 \pm 1.6 \mathrm{~mm}$ to $11.8 \pm$ $1.7 \mathrm{~mm}(p<0.001)$, DH-Anterior was increased from $9.6 \pm 2.3 \mathrm{~mm}$ to $13.4 \pm 2.1 \mathrm{~mm}(p<0.001)$, DH-Posterior was increased from $6.1 \pm 1.9 \mathrm{~mm}$ to $9.1 \pm 2.1 \mathrm{~mm}(p<0.001$ ), the slip ratio was reduced from $11.1 \pm 4.6 \%$ to $8.3 \pm 4.4 \%$ $(p=0.020)$ with the slip reduction ratio $25.6 \pm 32.3 \%$, and $\mathrm{SL}$ was slightly changed from $8.7 \pm 3.7^{\circ}$ to $8.3 \pm 3.0^{\circ}(p=$ 1.000). Following posterior fixation, the $\mathrm{DH}$ was unchanged (from $11.8 \pm 1.7 \mathrm{~mm}$ to $11.8 \pm 2.3 \mathrm{~mm}, p=1.000$ ), $\mathrm{DH}$ Anterior and DH-Posterior were slightly changed from $13.4 \pm 2.1 \mathrm{~mm}$ and $9.1 \pm 2.1 \mathrm{~mm}$ to $13.7 \pm 2.3 \mathrm{~mm}$ and $8.4 \pm$ $1.8 \mathrm{~mm}$ respectively $(P=0.861, P=0.254)$, the slip ratio was reduced from $8.3 \pm 4.4 \%$ to $2.1 \pm 3.6 \%(p<0.001)$ with the slip reduction ratio $57.9 \pm 43.9 \%$, and the $S L$ was increased from $8.3 \pm 3.0^{\circ}$ to $10.7 \pm 3.6^{\circ}(p=0.008)$.

Conclusions: Compared with stand-alone cage insertion, additional posterior fixation provides better segmental alignment improvement in terms of slip reduction and segmental lordosis in OLIF procedures in the treatment of lumbar degenerative spondylolisthesis.

Keywords: Spondylolisthesis, Interbody fusion, OLIF, Sagittal alignment, Slip reduction, Segmental lordosis

\footnotetext{
* Correspondence: syuqing2004@126.com

Department of Spine Surgery, Beijing Jishuitan Hospital, No. 31, Xinjiekou

East Street, Xicheng District, Beijing 100035, People's Republic of China

(c) The Author(s). 2021 Open Access This article is licensed under a Creative Commons Attribution 4.0 International License, which permits use, sharing, adaptation, distribution and reproduction in any medium or format, as long as you give appropriate credit to the original author(s) and the source, provide a link to the Creative Commons licence, and indicate if changes were made. The images or other third party material in this article are included in the article's Creative Commons licence, unless indicated otherwise in a credit line to the material. If material is not included in the article's Creative Commons licence and your intended use is not permitted by statutory regulation or exceeds the permitted use, you will need to obtain permission directly from the copyright holder. To view a copy of this licence, visit http://creativecommons.org/licenses/by/4.0/. The Creative Commons Public Domain Dedication waiver (http://creativecommons.org/publicdomain/zero/1.0/) applies to the data made available in this article, unless otherwise stated in a credit line to the data.
} 


\section{Background}

Lumbar degenerative spondylolisthesis is the anterior slip of one vertebral body on another in the presence of an intact neural arch [1] with underlying pathologies of segmental instability, anterior slip and spinal stenosis [2, 3]. Neural decompression and segmental stabilization are aims of surgical treatment, thus traditional surgical techniques involve direct neural decompression and instrumented fusion. As a recently developed minimally invasive technique for degenerative lumbar disease $[4,5]$, oblique lumbar interbody fusion (OLIF) can provide both direct and indirect neural decompression and segmental fusion, and gains the popularity in surgical treatment of degenerative spondylolisthesis.

Inserting a large cage into the intervertebral space, OLIF procedure can enlarge the canal and achieve indirect neural decompression by decreasing disc bulge and folds of ligamentum flavum [6]. Two techniques of OLIF procedure for degenerative spondylolisthesis were described in the literature, cage insertion with or without posterior fixation (stand-alone technique). Shortening surgical time without the cost of posterior fixation, stand-alone technique for selected patients is favored by some surgeons [7, 8]. However, the cage subsidence, migration and relatively high reoperation rate were reported $[9,10]$. The additional posterior fixation can provide more stability during the course of bony fusion without those complications of stand-alone technique [9].

Another advantage of posterior fixation lies on segmental alignment improvement. For mild to moderate slip degree of spondylolisthesis, inserting cage alone can partially reduce the slip due to tightening the surrounding ligamentous structures, thus improve the segmental alignment which may be further improved by additional posterior fixation with reduction maneuver. To the authors' knowledge, whether additional posterior fixation can further improve segmental alignment than did the stand-alone technique is unknown in the literature. The aim of this study is to assess the changes of segmental alignment following stand-alone cage insertion and additional posterior fixation in the same procedure setting for degenerative spondylolisthesis.

\section{Material and methods}

\section{Patients population}

Consecutive patients who had degenerative spondylolisthesis from L1 to L4 and underwent OLIF procedure with posterior pedicle screw fixation from July 2017 to August 2019 in the authors' hospital were retrospectively reviewed. Surgical indications for those patients were symptomatic radiculopathy or neurological claudication that were unresponsive to at least 3 months conservative treatments. Persistent mechanical low back pain and signs indicating segmental instability together with hypermobility suggested by flexion-extension lateral radiographs were confirmed before surgeries. Patients with isthmic spondylolisthesis, high grade spondylolisthesis (greater than Meyerding Grade 2 spondylolisthesis), degenerative scoliosis (Cobb angle > $30^{\circ}$ ) and L5 degenerative spondylolisthesis were excluded.

Selected patients underwent OLIF procedure with percutaneous pedicle screw fixation for indirect decompression. Indications for indirect decompression include: intermittent neurological symptoms can be resolved by lying down and rest; <Grade 4 facet joint osteoarthritis [11]; no bony lateral recess stenosis; no non-contained disc.

A total of 33 patients including 6 males and $27 \mathrm{fe}$ males, with an average age of $66.9 \pm 8.7$ years, were selected in this study. Twenty-one patients underwent one-level fusion, 9 two-level fusion and 3 multi-level ( $\geq$ three levels) fusion. Totally 36 slipped levels were assessed in this study. Preoperative slip ratio was $11.1 \pm 4.6 \%$ (Range: 3.5 to $23.0 \%$ ) on average. Eleven patients received indirect decompression and percutaneous pedicle screw fixation. The detailed characteristics of patients were shown in Table 1. All these selected patients have mid-term follow-up (postoperative 1 year) with intact pain and disability scores. Twenty-nine patients had postoperative plain and flexion-extension views of lumbar spine at postoperative 1 year. The study was approved by the ethical committee of the authors' hospital.

\section{Radiographic parameter measures}

Five radiographic parameters including disc height (DH), DH-Anterior, DH-Posterior, slip ratio and segmental lordosis (SL) were used to assess the segmental alignment of index level which were measured on the lateral views of fluoroscopic images that were obtained prior to cage insertion, following cage insertion and following posterior fixation. Taking L4/5 degenerative spondylolisthesis for example, the definition and measurement methods for radiographic parameters of interest are delineated as follows and illustrated on Fig. 1.

- Disc height (DH): Due to the inconsistency of fluoroscopic magnification, disc height cannot be measured directly on fluoroscopic images. The length of posterior wall of L4 vertebral body on the midsagittal cut of preoperative CT scans were chosen as a reference distance, $\mathrm{R} \mathrm{mm}$. A perpendicular line was drawn from the midpoint of superior endplate of L5 on the lateral fluoroscopic view. The distance between midpoint of L5 superior endplate and intersection point of this perpendicular line and L4 inferior endplate was measured as a mm. The length of posterior wall of L4 vertebral body was measured and recorded as $\mathrm{b} \mathrm{mm}$ on the lateral 
Table 1 Patient characteristics

\begin{tabular}{ll}
\hline No. of patients & 33 \\
Age (years) & $66.9 \pm 8.7$ \\
Female: Male & $27: 6$ \\
Fusion levels & 20 \\
One-level fusion & 10 \\
Two-level fusion & 3 \\
$\quad$ Multi-level fusion( $\geq 3$ levels fusion) & 2 \\
Slipped level & 4 \\
$\quad$ L2/3 & 30 \\
$\quad$ 33/4 & \\
$\quad$ 4/5 & $11.1 \pm 4.6$ \\
Average surgical time (minutes) & $199 \pm 49$ \\
Estimated blood loss (ml) & $209 \pm 99$ \\
Indirect decompression with percutaneous pedicle screw fixation & 11 (12 levels) \\
\hline
\end{tabular}

fluoroscopic view. $\mathrm{DH}$ was defined as $\mathrm{R} \times \mathrm{a} / \mathrm{b} \mathrm{mm}$. $\mathrm{DH}$-Anterior was defined as the vertical distance from posteroinferior corner of L4 vertebral body to superior endplate of L5. DH-Posterior was defined as the vertical distance from anterosuperior of L5 to the inferior endplate of L4.

- Slip ratio: A perpendicular line was drawn from the posteroinferior point of L4 vertebral body to the L5 superior endplate and the distance of from the intersection point to posterosuperior point of L5 vertebral body was measured and recorded as $\mathrm{c} \mathrm{mm}$ on the lateral fluoroscopic view. The slip ratio was defined as the ratio of $\mathrm{c}$ to the length of L5 superior endplate.

- Slip reduction ratio: defined as the change of slip ratio following cage insertion or posterior fixation divided by slip ratio prior to cage insertion.

- Segmental lordosis (SL): defined as angulation between the parallel lines of L4 superior endplate and L5 superior endplate on the lateral fluoroscopic view.

Preoperative CT scans and intraoperative fluoroscopic images were transferred into Carestream PACS (Version 11.0) and OsiriX Lite (Version 10.0.5) respectively. To ensure reliability of measurement, two observers received training of measurement on software workstation and the inter-observer reliability were assessed by interclass correlation coefficient (ICC). The ICC value were greater than 0.75 which indicated good reliability of measurement, and the average value of two observations was calculated for statistical analysis.

\section{OLIF procedure}

After general anesthesia, the patient was placed in right decubitus position. The center of intervertebral disc of the index level was identified under fluoroscopy and marked on skin. A skin incision was made $4-10 \mathrm{~cm}$ anterior to the center of index intervertebral disc. The musculature of abdominal wall was bluntly divided along the muscle fibers until the retroperitoneal space was reached. The psoas major and abdominal aorta were palpated and bluntly dissected through the interval between them by the surgeon's fingers. The tip of guiding wire was placed at the intervertebral space and confirmed under fluoroscopy. Afterwards, a serial of dilators was placed and the final pathway was established. The disc was incised and removed, followed by endplate preparations, implant trialing and grafting. Appropriate size of cage with 6 degrees of lordosis (Clydesdale Spinal System, Medtronic) was chosen and inserted into proper position which was confirmed under fluoroscopy.

Percutaneous pedicle screw fixation was performed in selected patients who met the criteria for indirect decompression, which was guided by computed navigation system or robotic system through stab incisions. Percutaneous reduction was performed following the manuals of the provider (Viper MIS Spine System, DePuy Spine). A pistol-grip reducer was used to apply internal reduction for the cranial screw after the caudal screws were tightened. If direct decompression was planned, posterior midline dissection and exposure was performed, followed by pedicle screw fixation and partial laminectomy. Reduction maneuvers by screw-rod construct were attempted for all cases. Following rod bending and tightening the caudal screw heads, the cranial screw heads were gradually tightened during reduction maneuver. No 

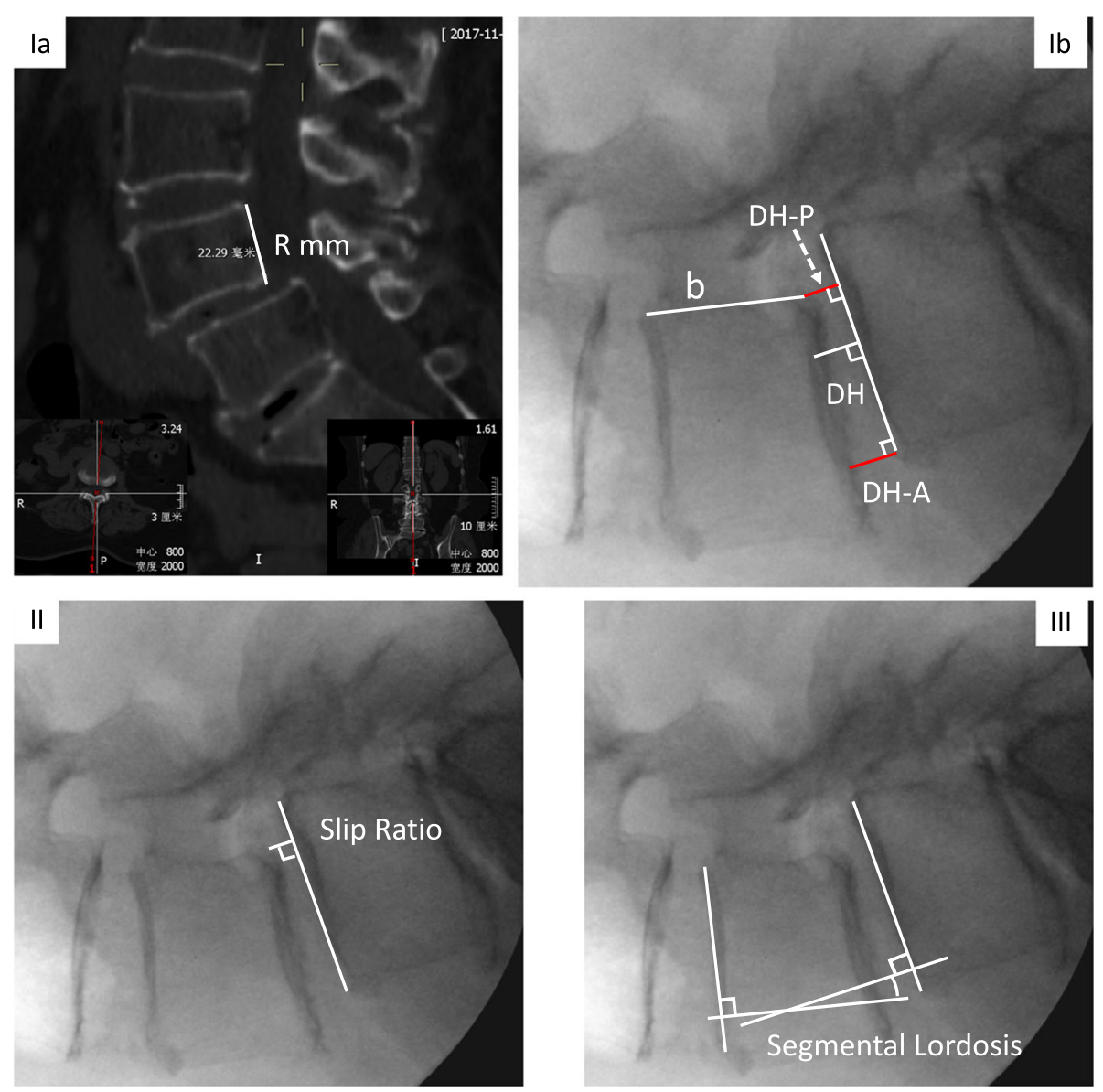

Fig. 1 The methods of measurement for Disc Height (DH), slip ratio and Segmental Lordosis (SL). la. The length of posterior wall of $L 4$ vertebral body were chosen as a reference, $\mathrm{R} \mathrm{mm}$. Ib. Draw a perpendicular line from the midpoint of superior endplate of $\mathrm{L} 5$. The distance between midpoint of $L 5$ superior endplate and intersection point of this perpendicular line and $L 4$ inferior endplate was measured as a $\mathrm{mm}$. Measure the length of posterior wall of $\mathrm{L} 4$ vertebral body as $\mathrm{b} \mathrm{mm}$. DH was $\mathrm{R} \times \mathrm{a} / \mathrm{b} \mathrm{mm}$. DH-A and DH-P were anterior and posterior distances of the overlapped disc space. II. draw a perpendicular line from the posteroinferior point of $L 4$ vertebral body to the $L 5$ superior endplate and measure the distance of intersection point and posterosuperior point of $L 5$ vertebral body as $\mathrm{c} \mathrm{mm}$. The slip ratio defined as the ratio of $\mathrm{C}$ to the length of $\mathrm{L} 5$ superior endplate. III. angulation between the lines of $L 4$ superior endplate and $L 5$ superior endplate

compressive force across pedicle screw heads to increase segmental lordosis was applied for all patients.

\section{Statistical analysis}

Statistical analysis was performed using SPSS Version 23.0 (IBM Corp, Chicago, Illinois). Categorical data were presented as numbers and/or ratio, while numerical data as mean and standard deviation. Statistical significance level was defined as $P<0.05$ on the basis of two-sided hypothesis test.

One-way ANOVA was used to compare the radiographic parameters prior to cage insertion, following cage insertion and following reduction maneuver. Multiple comparisons were performed for radiographic parameters prior to cage insertion and following cage insertion, as well as following cage insertion and following posterior fixation if one-way ANOVA result was statistically significant. Sub-group analysis was performed to compare the effect of open and percutaneous techniques of pedicle screw fixation on radiographic parameters by using ANOVA with repeated measures and Student $t$ test. Student paired $t$-test was used to compare the preoperative and postoperative pain and disability scores to assess the clinical improvement.

\section{Results}

Intraoperatively, with only anterior cage support, DH was increased from $8.2 \pm 1.6 \mathrm{~mm}$ to $11.8 \pm 1.7 \mathrm{~mm}(p<$ $0.001)$, DH-Anterior was increased from $9.6 \pm 2.3 \mathrm{~mm}$ to $13.4 \pm 2.1 \mathrm{~mm}(p<0.001)$, DH-Posterior was increased from $6.1 \pm 1.9 \mathrm{~mm}$ to $9.1 \pm 2.1 \mathrm{~mm}(p<0.001)$, the slip ratio was reduced from $11.1 \pm 4.6 \%$ to $8.3 \pm 4.4 \%$ ( $p=$ 0.020 ) with the slip reduction ratio $25.6 \pm 32.3 \%$, and SL was unchanged (from $8.7 \pm 3.7^{\circ}$ to $8.3 \pm 3.0^{\circ}, p=1.000$ ). 
Following posterior fixation, the $\mathrm{DH}$ was unchanged (from $11.8 \pm 1.7 \mathrm{~mm}$ to $11.8 \pm 2.3 \mathrm{~mm}, p=1.000$ ), $\mathrm{DH}$ Anterior and DH-Posterior were slightly changed from $13.4 \pm 2.1 \mathrm{~mm}$ and $9.1 \pm 2.1 \mathrm{~mm}$ to $13.7 \pm 2.3 \mathrm{~mm}$ and $8.4 \pm 1.8 \mathrm{~mm}$ respectively $(P=0.861, P=0.254)$, the slip ratio was reduced from $8.3 \pm 4.4 \%$ to $2.1 \pm 3.6 \%$ ( $p<$ 0.001 ) with the slip reduction ratio $57.9 \pm 43.9 \%$, and the SL was increased from $8.3 \pm 3.0^{\circ}$ to $10.7 \pm 3.6^{\circ}$ ( $p=$ 0.008). Radiographic parameters at different stages of OLIF procedures were shown in Table 2 and Fig. 2.

Two case examples of OLIF with open and percutaneous pedicle screw fixation were shown in Figs. 3 and 4.

The differences between the two groups of open and percutaneous techniques of pedicle screw fixation were analyzed. Among these five radiographic parameters, only DH-Anterior showed significant difference between two groups $(P=0.005)$ following ANOVA with multiple measures. The results of DH-Anterior prior to cage insertion and following posterior fixation were different between two groups $(P=0.019$ and $P=0.012)$ following Student $t$ test. The detailed results were shown on Table 3.

Preoperative Visual Analogue Scale (VAS) for back pain was $4.8 \pm 3.45$, VAS for leg pain $6.1 \pm 1.6$, Japanese Orthopaedic Association (JOA) score 15.9 \pm 6.1 and Oswestry Disability Index (ODI) $47.9 \pm 20.1 \%$. Postoperative VAS for back pain was $1.6 \pm 1.5$, VAS for leg pain $1.3 \pm 1.5$, JOA score $22.6 \pm 5.3$ and ODI $23.8 \pm 17.6 \%$ at 3 -month follow-up. Postoperative VAS for back pain was $0.8 \pm 1.0$, VAS for leg pain $1.1 \pm 1.7$, JOA score $24.1 \pm 5.6$, and ODI $14.2 \pm 13.5$ at 1-year follow-up. All the differences between preoperative and postoperative VAS, JOA score and ODI at 1-year follow-up were shown statistically significant by paired Student $t$ tests. The treatment effects at 1-year follow-up were 3.7 (95\% confidential interval $[\mathrm{CI}], 2.6-4.8)$ for VAS of back pain, 4.7 (95\% CI, 3.8-5.5) for VAS of leg pain, 8.5 (95\% CI, 5.8-11.2) for JOA score and 30.1 (95\% CI, 24.7-37.3) for ODI.
The postoperative complications were also evaluated, 4 patients complained transient weakness of hip flexion and numbness over the anterior thigh which disappeared within 3 months. Six patients complained of residual neurological deficit which was not relieved at postoperative 1 year. No obvious endplate subsidence $(>2 \mathrm{~mm}$ subsidence) or cage migration or pedicle screw loosening were observed on the lumbar radiographs at postoperative 1 year.

\section{Discussion}

In patients with degenerative spondylolisthesis, anterior displacement of inferior articular processes and osteophyte formation at superior articular process lead to lateral recess stenosis, while the displacement of the disc and thickening of ligamentum flavum cause central canal stenosis [3]. Choosing lumbar fusion for patients with symptomatic degenerative spondylolisthesis was challenged $[12,13]$, especially for degenerative spondylolisthesis without segmental instability. If lumbar fusion was necessary with the evidence of segmental instability, using mini-open oblique lateral approach, OLIF allows for large cage insertion which can result in reduction of disc bulging, the elongation of ligamentum flavum and thus enlarging lumbar spinal canal $[6,14,15]$. That's why indirect neural decompression could be achieved through this method.

\section{The slip reduced by OLIF}

The degree of slip negatively correlates with canal size and patients' quality of life preoperatively $[16,17]$. Although attempt for complete reduction of slip was not necessary in direct decompression procedure in terms of improving patient-reported outcomes [18], complete reduction of slip and restoring the normal anatomy of this segment can increase the canal size, meanwhile it can achieve indirect decompression in OLIF procedure with percutaneous pedicle screw fixation.

Table 2 Radiographic parameters of segmental alignment at different stages of OLIF procedures

\begin{tabular}{|c|c|c|c|c|c|c|}
\hline & $\begin{array}{l}\text { Prior to cage } \\
\text { insertion }\end{array}$ & $\begin{array}{l}\text { Following cage } \\
\text { insertion }\end{array}$ & $\begin{array}{l}\text { Following } \\
\text { posterior fixation }\end{array}$ & $P$ Value & $\begin{array}{l}\text { Comparison prior to Cage } \\
\text { insertion and following cage } \\
\text { insertion ( } P \text { Value) }\end{array}$ & $\begin{array}{l}\text { Comparison following cage } \\
\text { insertion and following } \\
\text { posterior fixation ( } P \text { value) }\end{array}$ \\
\hline Disc height (mm) & $8.2 \pm 1.6$ & $11.8 \pm 1.7$ & $11.8 \pm 2.3$ & $\begin{array}{l}< \\
0.001^{*}\end{array}$ & $<0.001^{*}$ & 1.000 \\
\hline $\begin{array}{l}\text { Disc height-Anterior } \\
(\mathrm{mm})\end{array}$ & $9.6 \pm 2.3$ & $13.4 \pm 2.1$ & $13.7 \pm 2.3$ & $\begin{array}{l}< \\
0.001^{*}\end{array}$ & $<0.001^{*}$ & 0.861 \\
\hline $\begin{array}{l}\text { Disc height-Posterior } \\
(\mathrm{mm})\end{array}$ & $6.1 \pm 1.9$ & $9.1 \pm 2.1$ & $8.4 \pm 1.8$ & $\begin{array}{l}< \\
0.001^{*}\end{array}$ & $<0.001^{*}$ & 0.254 \\
\hline Slip ratio (\%) & $11.1 \pm 4.6$ & $8.3 \pm 4.4$ & $2.1 \pm 3.6$ & $\begin{array}{l}< \\
0.001^{*}\end{array}$ & $0.020^{*}$ & $<0.001^{*}$ \\
\hline $\begin{array}{l}\text { Segmental lordosis } \\
\left({ }^{\circ}\right)\end{array}$ & $8.7 \pm 3.7$ & $8.3 \pm 3.0$ & $10.7 \pm 3.6$ & $0.006^{*}$ & 1.000 & $0.008^{*}$ \\
\hline
\end{tabular}

*Means statistically significant 


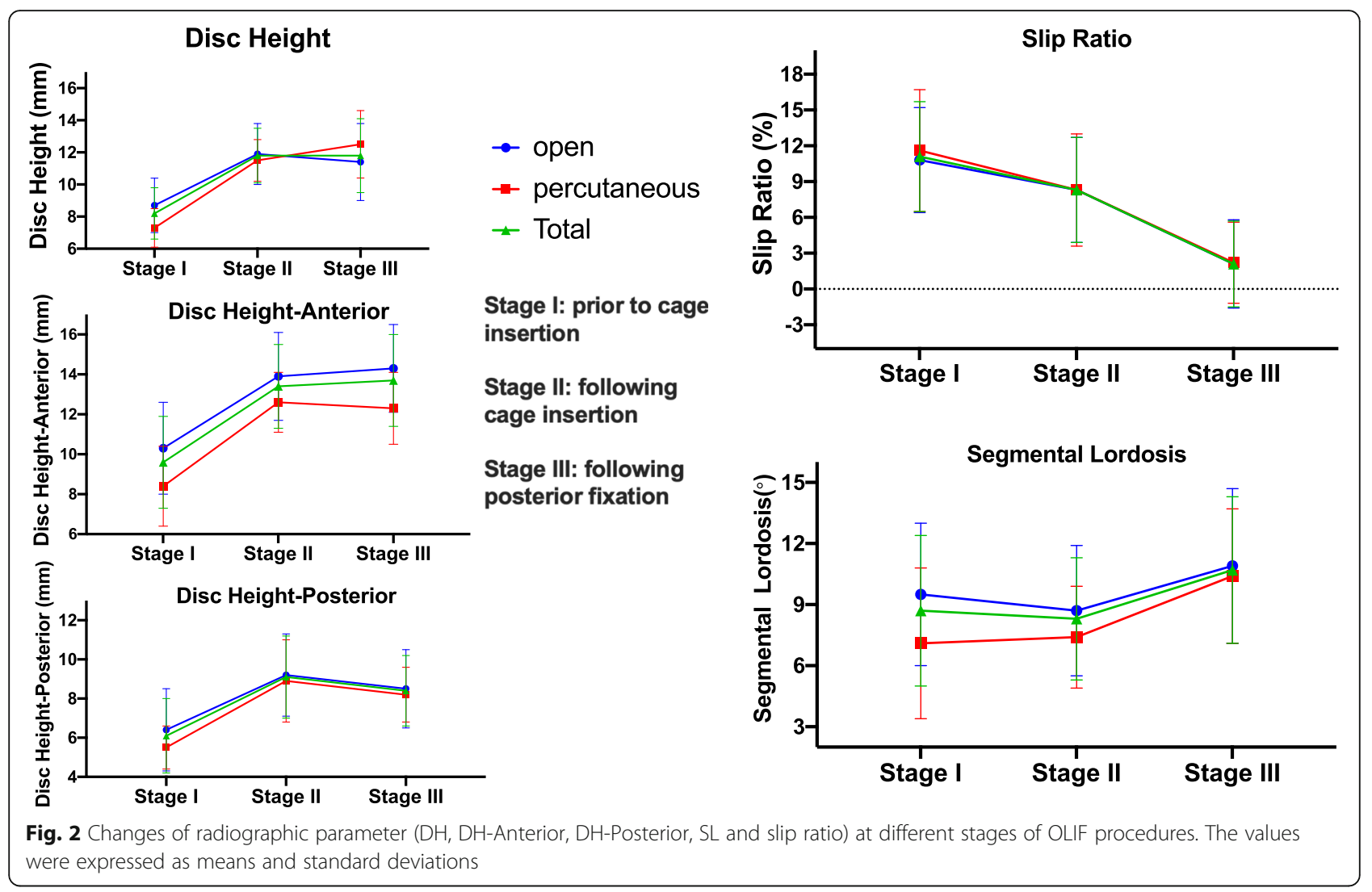

Sato et al [15] compared axial canal diameter, sagittal canal diameter and spinal canal cross-sectional area before and after OLIF procedures with posterior fixation for degenerative spondylolisthesis. Slip ratio was reduced from $14 \%$ preoperatively to $5 \%$ postoperatively and all those parameters of canal size were increased with slip reduction. As a result, reducing slip as much as possible can decompress the nerve impingement to the greatest extent, particularly necessary for indirect decompression in OLIF procedures.
Inserting large-size cage raises the disc height, hence stretches the ligamentous structures around the slipped level and reduces the slip. In this study, following cage insertion, disc height was improved from $8.2 \mathrm{~mm}$ to $11.8 \mathrm{~mm}$, while the slip ratio was improved from 11.1 to $8.3 \%$ and slip reduction ratio was $25.6 \%$ on average, which meant one quarter of slip were reduced by stand-alone cage insertion. These findings supported the mechanism of slip reduction by cage insertion alone. However, residual slip of $8.3 \%$ limits

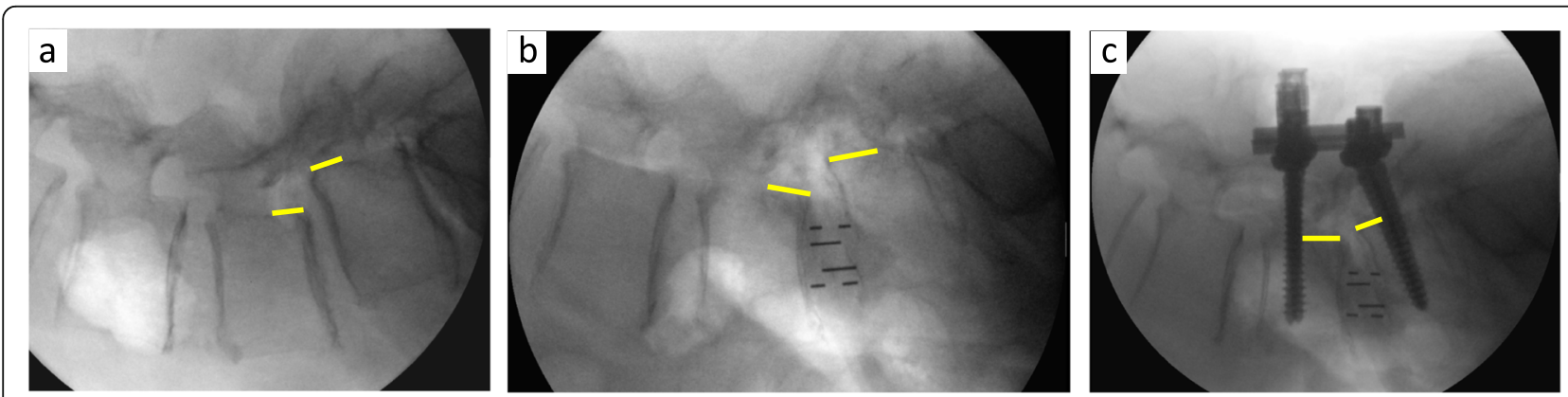

Fig. 3 The case example of OLIF with open pedicle screw fixation for degenerative spondylolisthesis. a. Prior to cage insertion. Disc height (DH) $6.7 \mathrm{~mm}$; Slip ratio 20.1\%; Segmental lordosis (SL) $14.7^{\circ}$. b. Following cage insertion. DH $8.4 \mathrm{~mm}$; Slip ratio 24.7\%; SL 18.5 . c. Following posterior fixation. DH $8.4 \mathrm{~mm}$; Slip ratio 6.5\%; SL $23.8^{\circ}$ 


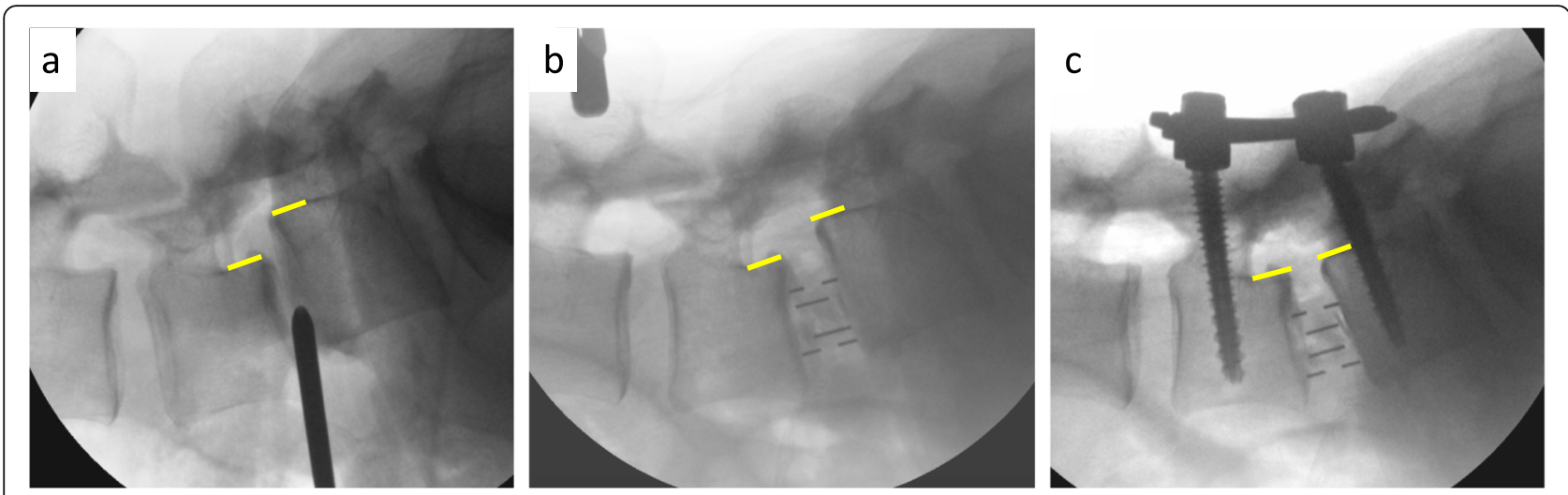

Fig. 4 The case example of OLIF with percutaneous pedicle screw fixation for degenerative spondylolisthesis. a. Prior to cage insertion. Disc height (DH) $4.4 \mathrm{~mm}$; Slip ratio 23.0\%; Segmental lordosis (SL) 0.7. b. Following cage insertion. DH $11.2 \mathrm{~mm}$; Slip ratio 16.4\%; SL 9.0 . c. Following posterior fixation. $\mathrm{DH} 12.7 \mathrm{~mm}$; Slip ratio $0 \%$; SL $17.4^{\circ}$

the stand-alone technique in terms of capacity of indirect nerve decompression.

In this study, following posterior fixation, the slip was further reduced to $2.1 \%$, slip reduction ratio was $57.9 \%$ on average, which meant greater than half of slip reduction was achieved by posterior fixation. Therefore, additional posterior fixation and reduction maneuver could reduce the slip to larger extent than stand-alone technique could.

\section{Segmental lordosis improved by OLIF}

Segmental lordosis can be improved by insertion of cage with lordotic angle design [19]. The magnitude of improvement correlates with preoperative segmental lordosis and anteroposterior position of cage [20]. This current study, however didn't show increase the segmental lordosis by cage insertion alone $\left(8.7^{\circ}\right.$ to $\left.8.3^{\circ}\right)$. The likely cause was that the large preoperative segmental lordosis $\left(8.7^{\circ}\right)$ limited the capacity of anterior realignment due to tightness of anterior

Table 3 Radiographic parameters of segmental alignment between open and percutaneous techniques of pedicle screw fixation

\begin{tabular}{|c|c|c|c|}
\hline Radiographic parameters & Prior to cage insertion & Following cage insertion & Following posterior fixation \\
\hline \multicolumn{4}{|l|}{ Disc height (mm) } \\
\hline Open & $8.7 \pm 1.7^{\mathrm{a}}$ & $11.9 \pm 1.9$ & $11.4 \pm 2.4$ \\
\hline Percutaneous & $7.3 \pm 1.2^{\mathrm{a}}$ & $11.5 \pm 1.3$ & $12.5 \pm 2.1$ \\
\hline Total & $8.2 \pm 1.6$ & $11.8 \pm 1.7$ & $11.8 \pm 2.3$ \\
\hline \multicolumn{4}{|l|}{ Disc height-Anterior ${ }^{\mathrm{b}}(\mathrm{mm})$} \\
\hline Open & $10.3 \pm 2.3^{\mathrm{a}}$ & $13.9 \pm 2.2$ & $14.3 \pm 2.2^{\mathrm{a}}$ \\
\hline Percutaneous & $8.4 \pm 2.0^{\mathrm{a}}$ & $12.6 \pm 1.5$ & $12.3 \pm 1.8^{\mathrm{a}}$ \\
\hline Total & $9.6 \pm 2.3$ & $13.4 \pm 2.1$ & $13.7 \pm 2.3$ \\
\hline \multicolumn{4}{|l|}{ Disc height-Posterior (mm) } \\
\hline Open & $6.4 \pm 2.1$ & $9.2 \pm 2.1$ & $8.5 \pm 2.0$ \\
\hline Percutaneous & $5.5 \pm 1.1$ & $8.9 \pm 2.1$ & $8.2 \pm 1.4$ \\
\hline Total & $6.1 \pm 1.9$ & $9.1 \pm 2.1$ & $8.4 \pm 1.8$ \\
\hline \multicolumn{4}{|l|}{ Slip ratio (\%) } \\
\hline Open & $10.8 \pm 4.4$ & $8.3 \pm 4.4$ & $2.1 \pm 3.7$ \\
\hline Percutaneous & $11.6 \pm 5.1$ & $8.3 \pm 4.7$ & $2.2 \pm 3.4$ \\
\hline Total & $11.1 \pm 4.6$ & $8.3 \pm 4.4$ & $2.1 \pm 3.6$ \\
\hline \multicolumn{4}{|l|}{ Segmental lordosis $\left(^{\circ}\right)$} \\
\hline Open & $9.5 \pm 3.5$ & $8.7 \pm 3.2$ & $10.9 \pm 3.8$ \\
\hline Percutaneous & $7.1 \pm 3.7$ & $7.4 \pm 2.5$ & $10.4 \pm 3.3$ \\
\hline Total & $8.7 \pm 3.7$ & $8.3 \pm 3.0$ & $10.7 \pm 3.6$ \\
\hline
\end{tabular}

${ }^{a}$ Means comparison of open and percutaneous techniques showed statistically significant

${ }^{\mathrm{b}}$ Means statistically significant following multivariate analysis between open and percutaneous techniques 
longitudinal ligament. Additional posterior fixation shortened the posterior column and further increased the segmental lordosis $\left(10.7^{\circ}\right)$ in this study, which indicated that posterior fixation could further improve segmental lordosis even if anterior realignment reached its limit.

\section{Stand-alone versus additional posterior fixation}

Stand-alone cage insertion of OLIF procedure without posterior fixation is advocated by some surgeons [7, 8]. Several clinical results favoring standalone technique were reported in the literature [7, 21], and those favorable outcomes depend on inserting a large cage which can both achieve indirect decompression effect and provide instant stability by axial loading [6]. However, some drawbacks of stand-alone technique were shown during follow-ups. Cage subsidence and subsequent loss of correction may occur without posterior fixation [8]. The effect of indirect decompression was also decreased during follow-up in some patients undergoing stand-alone techniques [10]. A recent meta-analysis showed the reoperation rate and occurrence of cage migration was higher for standalone technique [9].

OLIF with posterior fixation can enhance the segmental stability, decrease the rate of cage subsidence and migration, and maintain the instant indirect decompression effect by cage insertion [9]. Additionally, as this study revealed, posterior fixation for patients with degenerative spondylolisthesis can further reduce the slip that maximizes the effect of indirect decompression, together with improvement of segmental lordosis. Therefore, OLIF with additional posterior fixation was recommended for patients with degenerative spondylolisthesis.

\section{Limitations}

Although this study allows to demonstrate the changes of segmental alignment within the same procedure setting, this retrospective observational study has some limitations. Firstly, all the slip were Grade I spondylolisthesis (slip ratio: 3.5 to $23 \%$ ) with most slipped levels located at the L4/5 level, even if the inclusion criteria included Grade I and II slips, which may constrain drawing conclusion for Grade II slip or other segments. Secondly, additional fixation did improve the segmental alignment together with favorable symptoms and disability improvements in short-term, however, whether the improved segmental alignment or the superiority of posterior fixation can be maintained is still uncertain in longterm. Thirdly, the result of sagittal alignment changes was derived from combined analysis of open and percutaneous pedicle screw fixation due to relatively small sample size. Open and percutaneous fixation probably result in difference alignment changes. However, separate analysis showed consistent outcome between two groups, making the combined analysis reasonable.

\section{Conclusions}

Stand-alone cage insertion did have some degree of slip reduction and restoration of disc height. However, compared with stand-alone cage insertion, additional posterior fixation provides better segmental alignment improvement in terms of slip reduction and segmental lordosis in OLIF procedures in the treatment of lumbar degenerative spondylolisthesis.

\section{Abbreviations lordosis \\ Acknowledgements \\ Not applicable.}

OLIF: Oblique lumbar interbody fusion; DH: Disc height; SL: Segmental

\section{Authors' contributions}

JYW collected, analyzed, and interpreted the data and wrote the draft. YQS performed the surgery, designed the protocol, revised the draft. THG, NZ measured the radiographic parameters. All the authors have read and approved the final manuscript.

\section{Funding \\ This work was supported by Beijing Municipal Science \& Technology Commission (Z191100004419007) and Beijing JST Research Funding (XKGG201811).}

Availability of data and materials

The data used to support the findings of this study are available from the corresponding author upon request.

Ethics approval and consent to participate

This study protocol was established according to the ethical guidelines of the Helsinki Declaration and was approved by the Human Ethics Committee of Beijing Jishuitan Hospital. Written informed consent was obtained from each participant.

Consent for publication

Written informed consent for publication was obtained from each participant.

\section{Competing interests}

The authors declare that they have no known competing financial interests or personal relationships that could have appeared to influence the work reported in this paper.

Received: 18 August 2020 Accepted: 15 February 2021

Published online: 23 February 2021

\section{References}

1. Steven R, Garin FJE, Bell GR. Rothman-SIMEONE and HERKOWITZ'S the spine 7th ed. Philadelphia: Elsevier; 2018.

2. Koreckij TD, Fischgrund JS. Degenerative Spondylolisthesis. J Spinal Disord Tech. 2015:28(7):236-41.

3. Sengupta DK, Herkowitz HN. Degenerative spondylolisthesis: review of current trends and controversies. Spine (Phila Pa 1976). 2005;30(6 Suppl):S71-81.

4. Mayer HM. A new microsurgical technique for minimally invasive anterior lumbar interbody fusion. Spine (Phila Pa 1976). 1997;22(6):691-9 discussion 700.

5. Silvestre C, Mac-Thiong JM, Hilmi R, Roussouly P. Complications and morbidities of mini-open anterior retroperitoneal lumbar Interbody fusion: oblique lumbar Interbody fusion in 179 patients. Asian Spine J. 2012;6(2):89-97. 
6. Fujibayashi S, Hynes RA, Otsuki B, Kimura H, Takemoto M, Matsuda S. Effect of indirect neural decompression through oblique lateral interbody fusion for degenerative lumbar disease. Spine (Phila Pa 1976). 2015;40(3):E175-82.

7. Malham GM, Ellis NJ, Parker RM, Blecher CM, White R, Goss B, Seex KA. Maintenance of segmental Lordosis and disk height in stand-alone and instrumented extreme lateral Interbody fusion (XLIF). Clin Spine Surg. 2017; 30(2):E90-8.

8. Marchi L, Abdala N, Oliveira L, Amaral R, Coutinho E, Pimenta L. Radiographic and clinical evaluation of cage subsidence after stand-alone lateral interbody fusion. J Neurosurg Spine. 2013;19(1):110-8.

9. Alvi MA, Alkhataybeh R, Wahood W, Kerezoudis P, Goncalves S, Murad MH, Bydon M. The impact of adding posterior instrumentation to transpsoas lateral fusion: a systematic review and meta-analysis. J Neurosurg Spine. 2018;30(2):211-21.

10. Ozgur BM, Agarwal V, Nail E, Pimenta L. Two-year clinical and radiographic success of minimally invasive lateral transpsoas approach for the treatment of degenerative lumbar conditions. SAS J. 2010;4(2):41-6.

11. Fujiwara A, Tamai K, Yamato M, An HS, Yoshida H, Saotome K, Kurihashi A. The relationship between facet joint osteoarthritis and disc degeneration of the lumbar spine: an MRI study. Eur Spine J. 1999;8(5): 396-401.

12. Forsth $\mathrm{P}$, Olafsson $\mathrm{G}$, Carlsson T, Frost A, Borgstrom F, Fritzell P, Ohagen $P$, Michaelsson K, Sanden B, Randomized A. Controlled trial of fusion surgery for lumbar spinal stenosis. N Engl J Med. 2016:374(15):1413-23.

13. Sigmundsson FG, Jonsson B, Stromqvist B. Outcome of decompression with and without fusion in spinal stenosis with degenerative spondylolisthesis in relation to preoperative pain pattern: a register study of 1,624 patients. Spine J. 2015;15(4):638-46.

14. Oliveira L, Marchi L, Coutinho E, Pimenta L. A radiographic assessment of the ability of the extreme lateral interbody fusion procedure to indirectly decompress the neural elements. Spine (Phila Pa 1976). 2010;35(26 Suppl): S331-7.

15. Sato J, Ohtori S, Orita S, Yamauchi K, Eguchi Y, Ochiai N, Kuniyoshi K, Aoki Y, Nakamura J, Miyagi M, et al. Radiographic evaluation of indirect decompression of mini-open anterior retroperitoneal lumbar interbody fusion: oblique lateral interbody fusion for degenerated lumbar spondylolisthesis. Eur Spine J. 2017;26(3):671-8.

16. Kanno H, Aizawa T, Ozawa H, Koizumi Y, Morozumi N, Itoi E. An increase in the degree of olisthesis during axial loading reduces the dural sac size and worsens clinical symptoms in patients with degenerative spondylolisthesis. Spine J. 2018;18(5):726-33.

17. Wegmann K, Gundermann S, Siewe J, Eysel P, Delank KS, Sobottke R. Correlation of reduction and clinical outcome in patients with degenerative spondylolisthesis. Arch Orthop Trauma Surg. 2013;133(12): 1639-44.

18. Fan G, Zhang H, Guan X, Gu G, Wu X, Hu A, Gu X, He S. Patient-reported and radiographic outcomes of minimally invasive transforaminal lumbar interbody fusion for degenerative spondylolisthesis with or without reduction: a comparative study. J Clin Neurosci. 2016;33:111-8.

19. Melikian R, Yoon ST, Kim JY, Park KY, Yoon C, Hutton W. Sagittal plane correction using the lateral Transpsoas approach: a biomechanical study on the effect of cage angle and surgical technique on segmental Lordosis. Spine (Phila Pa 1976). 2016;41(17):E1016-21.

20. Otsuki B, Fujibayashi S, Takemoto M, Kimura H, Shimizu T, Murata K, Matsuda S. Analysis of the factors affecting lumbar segmental Lordosis after lateral lumbar Interbody fusion. Spine (Phila Pa 1976). 2020;45(14): E839-46.

21. Ahmadian A, Bach K, Bolinger B, Malham GM, Okonkwo DO, Kanter AS, Uribe JS. Stand-alone minimally invasive lateral lumbar interbody fusion: multicenter clinical outcomes. J Clin Neurosci. 2015;22(4):740-6.

\section{Publisher's Note}

Springer Nature remains neutral with regard to jurisdictional claims in published maps and institutional affiliations.

Ready to submit your research? Choose BMC and benefit from:

- fast, convenient online submission

- thorough peer review by experienced researchers in your field

- rapid publication on acceptance

- support for research data, including large and complex data types

- gold Open Access which fosters wider collaboration and increased citations

- maximum visibility for your research: over $100 \mathrm{M}$ website views per year

At BMC, research is always in progress.

Learn more biomedcentral.com/submissions 